\title{
Response diversity of free-floating plants to nutrient stoichiometry and temperature: Growth and resting body formation
}

Michael J McCann

Free-floating plants, like most groups of aquatic primary producers, can become nuisance vegetation under certain conditions. On the other hand, there is substantial optimism for the applied uses of free-floating plants, such as wastewater treatment, biofuel production, and aquaculture. Therefore, understanding the species-specific responses of floating plants to abiotic conditions will inform both management decisions and the beneficial applications of these plants. I measured the responses of three floating plant species common in the northeast United States (Lemna minor, Spirodela polyrhiza, and Wolffia brasiliensis) to nutrient stoichiometry (nitrogen and phosphorus) and temperature in the laboratory. I also used survey data to determine the pattern of species richness of floating plants in the field and its relationship with the dominance of this group. Floating plant species exhibited unique responses to nutrient stoichiometry and temperature in the laboratory, especially under low temperatures $\left(18^{\circ} \mathrm{C}\right)$ and low nutrient conditions $(0.5 \mathrm{mg}$ $\left.\mathrm{N} \mathrm{L}^{-1}, 0.083 \mathrm{mg} \mathrm{P} \mathrm{L}^{-1}\right)$. The three species displayed an apparent tradeoff with different strategies of growth or dormancy. In the field, water bodies with three or more species of floating plants were not more frequently dominated by this group. The response diversity observed in the lab may not be associated with the dominance of this group in the field because it is masked by environmental variability, has a weak effect, or is only important during transient circumstances. Future research to develop applied uses of floating plants should examine response diversity across a greater range of species or clones and environmental conditions. 
1 Title: Response diversity of free-floating plants to nutrient stoichiometry and temperature:

2 Growth and resting body formation

3 Author: Michael J. McCann ${ }^{\text {a, } 1}$

4 a Affiliation: Department of Ecology and Evolution, Stony Brook University, 650 Life Sciences

5 Building, Stony Brook, New York 11794-5245 USA

$6 \quad{ }^{1}$ Present address: Department of Marine and Coastal Sciences, Rutgers University, 71 Dudley

7 Road, New Brunswick, New Jersey 08901-8525 USA

8 E-mail: mccannmikejames@gmail.com 


\section{Abstract}

10 Free-floating plants, like most groups of aquatic primary producers, can become nuisance

11 vegetation under certain conditions. On the other hand, there is substantial optimism for the

12 applied uses of free-floating plants, such as wastewater treatment, biofuel production, and

13 aquaculture. Therefore, understanding the species-specific responses of floating plants to abiotic

14 conditions will inform both management decisions and the beneficial applications of these

15 plants. I measured the responses of three floating plant species common in the northeast United

16 States (Lemna minor, Spirodela polyrhiza, and Wolffia brasiliensis) to nutrient stoichiometry

17 (nitrogen and phosphorus) and temperature in the laboratory. I also used survey data to

18 determine the pattern of species richness of floating plants in the field and its relationship with

19 the dominance of this group. Floating plant species exhibited unique responses to nutrient

20 stoichiometry and temperature in the laboratory, especially under low temperatures $\left(18^{\circ} \mathrm{C}\right)$ and

21 low nutrient conditions $\left(0.5 \mathrm{mg} \mathrm{N} \mathrm{L}^{-1}, 0.083 \mathrm{mg} \mathrm{P} \mathrm{L}^{-1}\right)$. The three species displayed an apparent

22 tradeoff with different strategies of growth or dormancy. In the field, water bodies with three or

23 more species of floating plants were not more frequently dominated by this group. The response

24 diversity observed in the lab may not be associated with the dominance of this group in the field

25 because it is masked by environmental variability, has a weak effect, or is only important during

26 transient circumstances. Future research to develop applied uses of floating plants should

27 examine response diversity across a greater range of species or clones and environmental

28 conditions. 


\section{Introduction}

30 Free-floating plants (or simply "floating plants"), like most groups of aquatic primary producers,

31 can become nuisance vegetation under certain conditions (Portielje and Roijackers 1995, Janse

32 and Van Puijenbroek 1998, Scheffer et al. 2003, Smith 2012). Shallow lakes and ponds,

33 agricultural ditches, and tropical lakes can be dominated by thick mats of floating plants, altering

34 abiotic conditions and reducing biotic diversity (Morris and Barker 1977, Janes et al. 1996,

35 Morris et al. 2003, Verdonschot and Verdonschot 2013). The dominance of this functional group

36 is driven by nutrient enrichment (both nitrogen and phosphorus), and low levels of either of these

37 nutrients can limit floating plant growth (Portielje and Roijackers 1995, Kufel et al. 2010, Smith

38 2014). In addition to eutrophication, increased temperatures due to climate change may also

39 favor the dominance of this group over other primary producers (Netten et al. 2011, Peeters et al.

40 2013). On the other hand, there is substantial optimism for the applied uses of free-floating

41 plants, such as wastewater treatment, biofuel production, ecotoxicological assessment, and

42 aquaculture (e.g., Greenberg et al. 1992, Skillicorn et al. 1993, Ge et al. 2012, Xu et al. 2012,

43 Verma and Suthar 2014). Therefore, understanding the species-specific responses of floating

44 plants to nutrients and temperature will have both management implications and beneficial

45 applications (Ziegler et al. 2015). For example, if floating plant species exhibit response diversity

46 (i.e., unique response to abiotic conditions) (Elmqvist et al. 2003), then a more diverse

47 assemblage of floating plants may be more resilient or dominant (Naeem and Wright 2003), and

48 thus, harder to manage. Furthermore, if particular species have unique responses, than those with

49 a desirable suite of traits may be identified for applied uses. 
51 Although both nitrogen and phosphorus are important drivers of floating-plant dominance, the 52 ratio of both nutrients may have important consequences, especially in multi-species contexts

53 (Smith 2014). Depending on the conditions of the growth medium, species and clones of floating 54 plants differ in their N:P content (reviewed by Landolt and Kandler 1987). For example, Karpati 55 and Pomogyi (1979) reported N:P tissue content ranging from 2.65 for Lemna trisulca to 10.53 56 for Lemna minor in naturally growing plants. Docauer (1983) reported N:P content of 8.12 for 57 Spirodela polyrhiza, 10.38 for L. minor, and 3.46 and 6.54 for two species of Wolffia ( $W$.

58 borealis and $W$. columbiana, respectively) when the plants were growing at half of their 59 maximum growth rate. Depending on the nutrient content of the growth medium, tissue N:P in 60 Lemna gibba can range from approximately 3 to nearly 40 (Fulton et al. 2010). These species61 specific and context-dependent stoichiometric differences are important because nutrient 62 stoichiometry will differ depending on the source of nutrient loading and various other factors, 63 resulting in wide variation in nutrient stoichiometry of different water bodies (Downing and 64 McCauley 1992). If floating plant species are constrained in their nutrient stoichiometry, then 65 this may affect the outcome of competition among floating plants or with other primary producer 66 groups (Sterner and Elser 2002), although nitrogen alone explained most of the outcome of 67 competition among floating plants in the early stages of a field mesocosm experiment (Smith 68 2014).

70 I used laboratory experiments to determine the response diversity (i.e., unique response to abiotic 71 conditions) among floating plant species. To address this question, I performed two laboratory 72 experiments to examine the growth and turion-formation of floating plant species in response to 73 nitrogen, phosphorus, and temperature. The experiments were conducted with three of the most 
74 common floating plant species in the northeast United States: Lemna minor L., Spirodela 75 polyrhiza (L.) Schleid., and Wolffia brasiliensis Wedd. To understand whether the response

76 diversity in the laboratory corresponds to increased dominance in the field, I also analyzed a 77 dataset of over 200 freshwater lakes and ponds to determine the association between floating 78 plant species composition and richness and the occurrence of floating plant dominance. If 79 substantial differences exist among floating plant species in the lab, then a more diverse 80 assemblage may be more likely to be dominant over a broader range of conditions. In this case,

81 it is expected that water bodies with greater floating plant richness will be more frequently found 82 in a floating plant state.

83

\section{Materials \& Methods}

85 Laboratory conditions

86 Although conducting a single, large experiment to determine the response to all environmental 87 conditions of interest would have some advantages, I conducted two separate experiments to 88 allow for a manageable amount of effort and maintain adequate sample sizes in each experiment. 89 For all experiments, plants were collected from Setauket Mill Pond, East Setauket, New York, $90 \mathrm{USA}\left(40.946061^{\circ},-73.115613^{\circ}\right)$ and acclimated under experimental conditions prior to the start 91 of the experiments. Plants were collected in mid-August or mid-June for experiments I and II, 92 respectively. Species were identified according to Crow and Hellquist (2000). Modified Barko-

93 Smart media (Smart and Barko 1985; Szabó et al. 2005) with phosphorus supplied as potassium

94 dihydrogen phosphate and nitrogen supplied as a 1:1 ratio of nitrogen from nitrate and

95 ammonium (potassium nitrate and ammonium chloride) was used as the nutrient media.

96 Micronutrients were supplied to the media by Tropica Aquacare Plant Nutrition Liquid at a 
97 concentration of $0.1 \mathrm{~mL} \mathrm{~L}^{-1}$ (Szabó et al. 2003, 2010). Plants were grown in plastic, multiwell

98 plates with individual well diameters of $22.75 \mathrm{~mm}$ containing $4 \mathrm{~mL}$ of media. Each well housed

99 a single replicate of an experimental treatment. Multiwell plates were cleaned in $10 \%$

100 hydrochloric acid for at least 1 hour, and then rinsed thoroughly with deionized water prior to

101 using. Living plants (i.e., green) were moved to clean multiwell plates with fresh media every

102 two to four days, depending on the experiment. Any dead fronds (i.e., entirely white or brown)

103 were removed. Light was supplied at an intensity of $130-150 \mu \mathrm{E} \mathrm{m}^{-2} \mathrm{~s}^{-1}$ and a $14: 10 \mathrm{hr}$ light:dark

104 photoperiod, which is within the range of many previous studies (reviewed by Landolt and

105 Kandeler 1987). Temperature-controlled walk-in chambers were used to achieve the target

106 temperatures. Nutrient treatments and species were systematically assigned to wells to ensure

107 that replicates were dispersed across plates and not in adjacent wells. A systematic assignment of

108 treatments, rather than completely randomized, was used to reduce the likelihood that the wrong

109 nutrient medium or plant species would be placed in a well during each nutrient media change.

110 Because of the large number of replicates and the small spatial scale of the experimental setup, it

111 is unlikely that the systematic assignment of treatments correlated with an unknown,

112 confounding variable that varied along the same systematic spatial pattern of treatment

113 assignments. Initial plant area $\left(20 \mathrm{~mm}^{2}\right.$ or $5 \%$ of the total well area available for growth) was

114 approximately equal for all species within an experiment. Frond number differed because of the

115 size differences among species. In order to prevent crowding, experiments were ended when

116 plants in some treatments filled approximately two-thirds of the well area.

117

118 Raw data from both experiments are available in Supplemental Information 1 and 2. 
121 I measured the responses of floating plant species to nutrients and temperature by measuring

122 their growth (in terms of surface area) and turion formation at three nutrient levels (low: $0.5 \mathrm{mg}$

$123 \mathrm{~N} \mathrm{~L}^{-1}$ and $0.083 \mathrm{mg} \mathrm{P} \mathrm{L}^{-1}$; medium: $5 \mathrm{mg} \mathrm{N} \mathrm{L}^{-1}$ and $0.83 \mathrm{mg} \mathrm{P} \mathrm{L}^{-1}$; or high: $10 \mathrm{mg} \mathrm{N} \mathrm{L}^{-1}$ and 1.66

$\left.124 \mathrm{mg} \mathrm{P} \mathrm{L}{ }^{-1}\right)$ fully-crossed with three temperatures $\left(18,24\right.$, and $\left.30{ }^{\circ} \mathrm{C}\right)$, for a total of nine treatment

125 combinations. The three nutrient treatments are all at a N:P mass ratio of $\sim 6$ and correspond to

126 experimental treatments used in previous studies (e.g., Scheffer et al. 2003; Szabó et al. 2010).

127 At the lowest nutrient level, nutrients were expected to be limiting to growth (Lüönd 1983,

128 Szabó et al. 2010), but for the two highest nutrient levels, nutrients may be saturated (Szabó et al.

129 2010). Although this is not an exhaustive combination of treatments, these levels sample some of

130 the possible environmental conditions encountered by floating plants in nature, and potentially in

131 engineered applications (e.g., wastewater treatment). Eight replicates of each treatment

132 combination for each species were grown for 12 days. Plants were transferred to new nutrient

133 media 3, 5, 7, and 10 days after the start of the experiment.

135 Experiment II: Response to nutrient stoichiometry

136 In a second experiment, I measured the responses of floating plant species to nutrient

137 stoichiometry by measuring their growth and turion formation at all nine combinations of three

138 nitrogen $\left(0.5,5\right.$, and $\left.10 \mathrm{mg} \mathrm{N} \mathrm{L}^{-1}\right)$ and three phosphorus levels $\left(0.083,0.83\right.$, and $\left.1.66 \mathrm{mg} \mathrm{P} \mathrm{L}^{-1}\right)$,

139 producing a variety of N:P mass ratios, ranging from 0.30 to 120.48 (Table 1 ). At the lowest

140 treatment level of each nutrient, that nutrient may limit plant growth. Six replicates of each plant

141 species at each of the nine nutrient treatments were grown for 17 days. A smaller number of

142 replicates per each treatment combination (6 vs. 8 replicates) were used in this experiment 
143 because of the relatively low variance observed in Experiment I. I transferred plants to new

144 nutrient media $3,7,10$, and 14 days after the start of the experiment. Plants were grown at

145 approximately $30^{\circ} \mathrm{C}$, which had similar growth rates as the $24^{\circ} \mathrm{C}$ treatment and resulted in the

146 maximum growth rates in Experiment I. This temperature would ensure that only nutrient

147 stoichiometry would limit plant growth in this experiment.

148

149

\section{Growth and turion production}

150 To quantify growth, plants in each replicate of each treatment were photographed (Nikon

151 Coolpix 5700 Digital Camera) with backlighting from a light box (Laboratory Supply Company,

15260 Watts) on days that nutrient media were changed. The two-dimensional plant area on the

153 water surface was measured with ImageJ, version 1.47 (Rasband 2014), using the threshold

154 function on an 8-bit grayscale photo, after dead fronds had been removed by hand (see above).

155 Relative growth rate (RGR) was calculated between each measurement. RGR was calculated as

$156\left[\ln \left(\mathrm{A}_{2}\right)-\ln \left(\mathrm{A}_{1}\right)\right] /\left(\mathrm{t}_{2}-\mathrm{t}_{1}\right)$, where $A$ is the area of plants in $\mathrm{mm}^{2}, t$ is time in days, and subscripts 2

157 and 1 indicate two sequential time points in the experiment. Plant thickness or mass was not

158 measured during these experiments, but the overheard surface area is a commonly used measure

159 in many experiments (reviewed by Landolt and Kandeler 1987). Turions were distinguished as

160 plants that had sunk to the bottom of the experimental vessel, and they typically differed in size,

161 texture, or color from plants on the surface. The number of turions (i.e., asexual resting bodies)

162 produced were counted for each experimental replicate after the live plants had been moved to

163 fresh media. The number of turions was converted to area with equations developed in another

164 study (Supplemental Information 3). In some replicates, all plants in a replicate died (i.e.,

165 bleached white) during the experiment, and were re-started with new plants, assuming that the 
166 failed growth was due to damage to the plant when handling. These replicates were excluded

167 from analysis if they were not grown for at least 10 days.

168

169 Statistical analysis

170 For all ANOVAs, data were tested for normally distributed residuals with a Shapiro-Wilk test

171 and equal variance among treatment groups with Levene's test. If the data did not meet these

172 assumptions of ANOVA, they were power transformed to ensure that these criteria were met. I

173 performed all statistical analyses in R version 3.0.2 (R Development Core Team 2013).

174

175 The goal of these experiments was to test whether floating plant species differed in their

176 response to environmental conditions and under what conditions they differed. Therefore,

177 analyses tested for differences between species under particular combinations of environmental

178 conditions (i.e., treatment levels). For both experiments, I performed a one-way ANOVA for

179 each treatment combination to test for an effect of species on the average RGR. I used a Dunn-

180 Šidák correction to adjust p-values for multiple comparisons. When significant treatment effects

181 were found, Tukey's HSD was used to detect differences among species. An alternative

182 approach to analyzing these data is to use factorial ANOVAs to test for the main and interactive

183 effects of species and experimental conditions on growth rates (Supplemental Information 4).

184 Since the number of possible pairwise, posthoc comparisons in each experiment is large (351)

185 and species differences under identical conditions (i.e., response diversity) was the focus of this

186 study, this statistical approach is not reported in the main text. 
188 In the first experiment (the effect of nutrients and temperature) only $W$. brasiliensis formed 189 turions. I analyzed the effect of nutrients and temperature on turion area produced $\left(\mathrm{mm}^{2} \mathrm{day}^{-1}\right)$ 190 by $W$. brasiliensis with a two-way ANOVA. When significant treatment effects were found, I 191 used Tukey's HSD to detect differences among treatment levels. In the second experiment (i.e., 192 the effect of nitrogen and phosphorus), W. brasiliensis formed turions under all treatment levels 193 and S. polyrhiza under some treatment levels. To detect differences in turion production rate 194 between species at particular nutrient levels, I used one-way ANOVAs at each nutrient level 195 where both $W$. brasiliensis and S. polyrhiza formed turions. I used a Dunn-Šidák correction to 196 adjust $\mathrm{p}$-values for multiple comparisons.

Floating plant richness and abundance in natural water bodies

199 I examined the occurrence and dominance of floating plant species in lakes and ponds with a 200 dataset of 205 freshwater water bodies in Connecticut and Long Island, NY (Supplemental 201 Information 5). The data came from two sources: 1) 184 surveys by the Connecticut Agricultural 202 Experiment Station (CAES) in 2005 to 2013, and 2) 21 surveys that I conducted in Long Island, 203 New York and Connecticut, USA in 2011 to 2013. This data set spanned a range of perennial, 204 freshwater lakes and ponds and included the list of floating plant species present in the water 205 body and the maximum floating plant cover (percent of water body covered as quantified 206 through visual observation and mapping) during the late summer (late July to September). See 207 Capers et al. (2007) for a description of the survey methods used for the CAES data. For the 208 Long Island surveys, plant cover was estimated through visual observation similar to methods 209 used in previous studies (Driever et al. 2005, Smith 2012). In this study, I use high floating plant 210 cover as a surrogate for dominance by floating plants, while acknowledging that a consideration 
211 of other primary producers (e.g., phytoplankton, submerged vegetation) and covariates is

212 necessary for a rigorous demonstration of complete floating-plant dominance.

213

214 I used a goodness of fit test (G-test, based on a chi-square) to test if all floating plant species

215 richness levels were equally likely to occur (i.e., random), excluding water bodies without

216 floating plants. I used a second G-test to determine if floating plant dominance ( $\geq 66.67 \%$ cover)

217 was equally likely to occur under different levels of floating plant richness. The expected value

218 for each richness level in water bodies dominated by floating plants was based on the observed

219 frequency of each floating plant richness level across all water bodies (both dominated and non-

220 dominated). Floating plant richness was categorized as 1, 2, or $\geq 3$ species to ensure adequate

221 sample sizes in each level.

222

\section{Results}

224 Experiment I: Response to nutrients and temperature

225 Average relative growth rate (RGR) was different among species at six of the nine combinations

226 of nutrients and temperature (Table 2, Figure 1). Species growth rates were equal when nutrients

227 and temperatures were high $\left(10 \mathrm{mg} \mathrm{N} \mathrm{L}^{-1}\right.$ and $1.66 \mathrm{mg} \mathrm{P} \mathrm{L}^{-1}$ and 24 or $\left.30{ }^{\circ} \mathrm{C}\right)$ or at $18^{\circ} \mathrm{C}$ and

228 medium nutrients ( $5 \mathrm{mg} \mathrm{N} \mathrm{L}^{-1}$ and $0.8 \mathrm{mg} \mathrm{P} \mathrm{L}^{-1}$ ). Typically, Lemna minor and Spirodela

229 polyrhiza growth rates were equal to each other and both were greater than the growth rate of

230 Wolffia brasiliensis (Figure 1). Only W. brasiliensis formed turions in this experiment. There

231 was a significant effect of nutrients $\left(F_{2,64}=4.770, p=0.012\right)$, temperature $\left(F_{2,64}=38.706, p<\right.$

$2320.001)$, and significant interaction $\left(\mathrm{F}_{4,64}=4.089, \mathrm{p}=0.005\right)$ on the turion production rate of $W$. 
233 brasiliensis (Figure 2). At both 18 and $30^{\circ} \mathrm{C} W$. brasiliensis decreased turion production at the 234 highest nutrient level, but at $24{ }^{\circ} \mathrm{C}$ turion production increased with nutrient level (Figure 2). 235

236 Experiment II: Response to nutrient stoichiometry

237 Average RGR differed among species in four of the nine nutrient combinations (Table 3, Figure 238 3). Species differences were found whenever nitrogen was low $\left(0.5 \mathrm{mg} \mathrm{N} \mathrm{L}^{-1}\right)$ or when 239 phosphorus was low and nitrogen was medium (0.08 $\mathrm{mg} \mathrm{P} \mathrm{L}^{-1}$ and $\left.5 \mathrm{mg} \mathrm{N} \mathrm{L}^{-1}\right)$. Both $S$.

240 polyrhiza and $W$. brasiliensis formed turions in this experiment. $W$. brasiliensis formed turions at 241 all combinations of nitrogen and phosphorus, whereas S. polyrhiza only formed turions at low 242 nitrogen and medium and high phosphorus or low phosphorus and medium and high nitrogen

243 (Figure 4). At low nitrogen and medium phosphorus (ANOVA, $\mathrm{F}_{1,9}=51.62, \mathrm{p}<0.001$ ), low 244 nitrogen and high phosphorus (ANOVA, $\mathrm{F}_{1,10}=49.91, \mathrm{p}<0.001$ ), and medium nitrogen and low 245 phosphorus (ANOVA, $\mathrm{F}_{1,10}=49.82, \mathrm{p}<0.001$ ), $W$. brasiliensis had a greater turion production 246 rate than S. polyrhiza (Figure 4). Only at low phosphorus and high nitrogen both species had 247 equal turion production rates (ANOVA, $\left.\mathrm{F}_{1,6}=6.64, \mathrm{p}=0.042\right)$ (Dunn-Šidák adjusted critical p248 value 0.013$)$

249

250 Floating plant richness and abundance in natural water bodies

251 Most freshwater lakes and ponds in Connecticut and Long Island, NY did not have any floating 252 plants present (106 of 205, Table 4). Across all water bodies with floating plants present, a total 253 of seven taxa were found. L. minor, S. polyrhiza, and Wolffia spp. were the most common taxa, 254 occurring in 82,47 , and 42 of the 205 water bodies, respectively. The next most common 255 species, L. trisulca, only occurred in 4 lakes and ponds. Among water bodies with floating 
256 plants present, the occurrence of different levels of species richness levels was non-random

257 (Table 4, Figure 5a, G-test, $\mathrm{G}=6.909, \mathrm{df}=2, \mathrm{p}<0.031$ ). Monocultures were more common than 258 expected and three- and four-species polycultures were less common than expected (Table 4, 259 Figure 5a).

260

261 Only twenty water bodies had floating plant cover greater than $66.67 \%$. Among these water 262 bodies, there was no significant association between floating plant richness categories and the 263 frequency of occurrence (Table 4, Figure $5 b, \mathrm{G}$-test, $\mathrm{G}=2.430, \mathrm{df}=2, \mathrm{p}=0.7$ ). Although not 264 statistically significant, water bodies dominated by floating plants tended to have three or more 265 species of floating plants; whereas, water bodies not dominated by floating plants tended to have 266 one or two species (Figure 5b). The results of these analyses did not change if a higher threshold 267 for floating plant dominance (e.g., $80 \%$ cover) was used or if the analysis was limited to small 268 water bodies ( $<5$ ha surface area) or water bodies with higher nutrients (total phosphorus $>0.02$ $\left.269 \mathrm{mg} \mathrm{P} \mathrm{L}{ }^{-1}\right)$.

270

\section{Discussion}

272 In general, the floating plant species in this study exhibited differences (i.e., response diversity) 273 in their average growth rates across nitrogen, phosphorus, and temperature conditions.

274 Differences among species were typically seen under less favorable conditions (i.e., low 275 nutrients and low temperatures), whereas, species typically had similar growth rates under 276 conditions expected to be most favorable for their growth (i.e., high nutrients and high 277 temperature). When differences were detected, Lemna minor and Spirodela polyrhiza typically 278 grew at rates that were equal to each other and higher than Wolffia brasiliensis. On the other 
279 hand, $W$. brasiliensis produced more resting bodies across most experimental conditions,

280 whereas S. polyrhiza only occasionally produced turions. L. minor never produced turions in

281 these experiments. This suggests a tradeoff between producing floating or sinking biomass under

282 these experimental conditions and may explain the lower relative growth rate of $W$. brasiliensis.

283 In the field, a floating plant-dominated state did not occur more frequently in water bodies with

284 higher floating plant richness, opposite to the expectation if response diversity is important for

285 formation of floating plant dominance.

286

287 The apparent tradeoff between growth and resting body production among floating plant species

288 may have important consequences for this functional group. The different strategies among

289 species can allow the floating plant functional group as a whole to have both rapid growth on the

290 water surface and insurance against perturbation via their resting bodies. Therefore, floating

291 plant polycultures may have a combination of strategies that may not be achievable by a single

292 species. For example, the floating plant functional group in a water body with both L. minor and

293 W. brasiliensis could have both faster growth at low nutrients or temperatures (due to the traits of

294 L. minor) and a greater number of resting bodies to re-colonize the water body at the start of a

295 growing season (due to the traits of $W$. brasiliensis). A polyculture of floating plant species and

296 their unique responses to environmental conditions may allow the functional group to attain

297 higher biomass or persist in a water body over a broader range of conditions.

298

299 Although, response diversity in the lab did not translate to a correlation between floating plant-

300 dominance and higher floating plant richness in the field, the response diversity may be relevant

301 for applied uses of these plants (e.g., wastewater treatment, biofuel production, and aquaculture). 
302 While the optimal species or combination of species will depend on the particular application,

303 some general patterns exist. For example, if maximization of floating plant surface growth is the

304 sole objective (e.g., a highly controlled application where biomass is harvested), then either $L$.

305 minor or S. polyrhiza would be a better choice than $W$. brasiliensis because of their higher

306 growth rates. Future experiments would need to determine whether a combination of these two

307 species or a monoculture would be optimal. On the other hand, if formation of resting bodies was

308 a desirable property in the application (e.g., perennial, outdoor uses), then including S. polyrhiza,

309 W. brasiliensis, or another species that produces turions would be recommended. For some

310 applied uses of floating plants, other types of experiments need to be conducted. For example,

311 use in combined aquaculture systems with fish would require an understanding of the preference

312 and nutritional attributes of plant species with regards to the fish species.

313

314 The lack of a relationship between response diversity of this functional group and its ability to

315 become dominant may be due to a variety of factors. In the field, environmental variability may

316 outweigh the relationship between species richness and the formation of the floating plant state.

317 In addition to response diversity, other factors will influence the occurrence of the floating plant

318 state in the field. For example, water bodies in the northeast United States above a size threshold

319 ( $\sim$ ha) are rarely dominated by floating plants (McCann, personal observation). It is also

320 possible that the floating plant response diversity observed in the laboratory only has a small

321 effect on dominance in the field. Although species differences are quantifiable in the laboratory,

322 their magnitude may not be large enough to be detectable in the field. Furthermore, since

323 floating plant dominance is relative uncommon in this region $(<10 \%$ of water bodies), there may 
324 be low statistical power to detect a relationship between species richness and floating plant

325 dominance, especially if effect sizes are small.

326

327 It is also possible that response diversity is only important during transient circumstances or 328 conditions rarely encountered in these surveys. Therefore, the response diversity exhibited by

329 floating plant species in the lab will not determine whether this functional group is currently in a 330 dominant state in the field. As a result, species-rich water bodies could lose floating plant species

331 due to local extinction and still maintain floating plant dominance. Response diversity may also

332 help this functional group form a dominant state in other geographic regions where low

333 temperatures and low nutrients are more common (e.g., the Upper Midwest United States).

334 Rather than allowing floating plants to achieve dominance, the response diversity observed may

335 help this functional group persist in a water body, despite unfavorable conditions. Interestingly,

336 L. minor, which did not produce resting bodies in the lab but typically had the fastest growth rate

337 (along with S. polyrhiza), was the most common floating plant species in this region (present in

33882 of 205 water bodies). Despite differences in growth rates and resting body production, $S$.

339 polyrhiza and $W$. brasiliensis occurred in a similar number of water bodies (47 and 42,

340 respectively).

341

342 The lower growth rates observed in Experiment II (Figure 3) relative to Experiment I (Figure 1)

343 may be due to the fact that the nutrient media was changed less frequently (every 3-4 days

344 compared to 2-3 days) and nutrient levels likely decreased to a greater extent between media

345 changes in Experiment II. Also, S. polyrhiza only produced turions in Experiment II. The

346 difference in media change frequency may have caused the difference in turion production 
347 between experiments, or there may be differences based on the timing when plants were

348 collected from the field (Mid-August and mid-June for Experiments I and II, respectively).

349 Therefore, strict comparison of the growth rates or turion production between experiments

350 should not be done without consideration of the differences in experimental conditions.

351

352 There are few others studies of the response diversity of the floating plant functional group to

353 temperature, nutrients, or other environmental variables. Lüönd (1983) measured the response of

354 L. minor, S. polyrhiza, and two other species of Lemna to nitrogen and phosphorus at $25^{\circ} \mathrm{C}$. All

355 species increased their growth rates in response to increases of both nutrients, as in this study, 356 and all species decreased their growth rate at extremely high nutrient levels (e.g., $1.75 \mathrm{~g} \mathrm{~N} \mathrm{~L}^{-1}$,

$3571.36 \mathrm{~g} \mathrm{P} \mathrm{L}^{-1}$ ) (Lüönd 1983). The presence, but not the rate, of turion production was reported for

358 S. polyrhiza. Unfortunately, no statistical comparisons were made to determine if species had

359 unique responses under particular conditions (Lüönd 1983). Lemon et al. (2001) examined the

360 growth of L. minor, S. polyrhiza, and W. borealis, a cogener of $W$. brasiliensis at $24^{\circ} \mathrm{C}$ and very

361 high nutrients (33\% v/v Hutner's medium, $\left.\sim 31 \mathrm{mg} \mathrm{N} \mathrm{L}^{-1}, \sim 23 \mathrm{mg} \mathrm{P} \mathrm{L}^{-1}\right)$, and found that $W$.

362 borealis has the highest growth rate, while S. polyrhiza has the lowest (in terms of frond number,

363 not area growth rate). Results of turion production were not reported (Lemon et al. 2001). Some

364 studies have examined response diversity to variables not included in this study. Floating plants

365 appear to have response diversity to $\mathrm{pH}$ (Hicks 1932, McClay 1976). Lemna minor, Spirodela

366 oligorrhiza, and Wolffia arrhiza all have a similar $\mathrm{pH}$ range ( $\mathrm{pH} \sim 3$ to 10$)$, but their optimal $\mathrm{pH}$

367 differs, from mildly acidic (W. arrihiza, $\mathrm{pH} 5.0$ or L. minor $\mathrm{pH} 6.2$ ) to neutral (S. oligorrhiza, $\mathrm{pH}$

368 7.0) when grown in the lab at $25^{\circ} \mathrm{C}$ at very high nutrients ( $\sim 241 \mathrm{mg} \mathrm{N} \mathrm{L}^{-1}$ and $\left.\sim 32 \mathrm{mg} \mathrm{P} \mathrm{L}^{-1}\right)$

369 (McClay 1976). 
371 While this study was only able to examine a subset of all floating plant species under particular

372 combinations of environmental conditions, it found some conditions where species have

373 response diversity and others where species are redundant. Further studies, including a greater

374 number of species or clones and environmental variables, as well as determining tradeoffs

375 between responses (e.g., growth or resting bodies), are necessary to determine the full breadth of 376 response diversity of this functional group. For example, previous work on floating plant

377 performance under low temperature conditions $\left(\sim 10^{\circ} \mathrm{C}\right)$ shows that species differ in their

378 minimum temperature (Landolt and Kandeler 1987), which may have important consequences

379 for growth of this functional group at the beginning and end of a growing season. While Ziegler 380 et al. (2015) examined the maximum relative growth rate of 39 clones of 13 species in all five 381 floating plant genera under a single set of nutrient temperature conditions, future research efforts

382 should systematically examine floating plant response diversity in a larger number of clones and 383 environmental conditions. Future work should also consider variability in environmental 384 conditions and species composition through space and time. Floating plants are expected to be

385 386 387 plant dominance.

389 Conclusions

390 This study has identified differences in three floating plant species common to the northeast

391 United States. Although species differences existed in the laboratory, there was no statistical

392 support that the species richness of floating plants increases their dominance in the field. 
393 Although free-floating plants can be viewed as both a nuisance and an opportunity for applied

394 uses, understanding the species-specific responses of these plants to abiotic conditions is 395 essential for both management and applications.

396

397 Acknowledgements

398 I would like to thank Ishmael Rahim and Eunice Asare for help with the laboratory experiments, 399 Greg Bugbee and the Connecticut Agricultural Experiment Station for data access, and The 400 Frank Melville Memorial Park Foundation, numerous property owners, and the Suffolk County 401 Parks Department for access to water bodies. This manuscript was improved by feedback from 402 Dianna Padilla, Stephen Baines, Heather Lynch, and Gary Mittelbach.

403

404 Supplemental Information

405 Supplemental Information 1. Raw data from experiment I.

406 Supplemental Information 2. Raw data from experiment II.

407 Supplemental Information 3. Converting from turion number to turion area

408 Supplemental Information 4. Analysis of growth rates using factorial ANOVAs.

409 Supplemental Information 5. Properties of 205 surveyed water bodies. 410 


\section{References}

413 Barrat-Segretain MH. 1996. Strategies of reproduction, dispersion, and competition in river $414 \quad$ plants: A review. Vegetatio 123: 13-37.

415 Capers RS, Selsky R, Bugbee GJ, White JC. 2007. Aquatic plant community invisibility and 416 scale-dependent patterns in native and invasive species richness. Ecology 88: 3135-3143.

417 Crow GE, Hellquist CB. 2000. Aquatic and wetland plants of Northeastern North America: Volume 2. Angiosperms: Monocotyledons. Madison: University of Wisconsin Press.

Docauer DM. 1983. A nutrient basis for the distribution of the Lemnaceae. Ph.D. Dissertation, University of Michigan.

Downing JA, McCauley E. 1992. The nitrogen: phosphorus relationship in lakes. Limnology and Oceanography 37: 936-945.

Driever SM, Van Nes EH, Roijackers RMM. 2005. Growth limitation of Lemna minor due to high plant density. Aquatic Botany 81: 245-251.

Elmqvist T, Folke C, Nyström M, Peterson G, Bengtsson J, Walker B, Norberg J. 2003. Response diversity, ecosystem change, and resilience. Frontiers in Ecology and the Environment 1: 488-494. to nutrient and chemical stressors: Differential effects of triclosan on internal stoichiometry and nitrate uptake across a nitrogen:phosphorus gradient. Environmental Toxicology and Chemistry 29: 2363-2370.

Ge X, Zhang N, Phillips GC, Xu J. 2012. Growing Lemna minor in agricultural wastewater and converting the duckweed biomass to ethanol. Bioresource Technology 124: 485-488. 
434 Greenberg BM, Huang XD, Dixon DG. Applications of the aquatic higher plant Lemna gibba for 435 ecotoxicological risk assessment. Journal of Aquatic Ecosystem Health 1: 147-155.

436 Hicks LE. 1932. Ranges of pH tolerance of Lemnaceae. Ohio Journal of Science 32: 237-244.

437 Hillman WS. 1961. The Lemnaceae, or duckweeds: A review of the descriptive and experimental $438 \quad$ literature. Botanical Review 27: 221-287.

439 Janes RA, Eaton JW, Hardwick K. 1996. The effects of floating mats of Azolla filiculoides Lam. 440 and Lemna minuta Kunth on the growth of submerged macrophytes. Hydrobiologia 340: 23-26.

442

443

444

445

446

447

448

449

450

451

452

453

454

Janse JH, Van Puijenbroek PJTM. 1998. Effects of eutrophication in drainage ditches. Environmental Pollution 102: 547-552.

Karpati V, Pomogyi P. 1979. Accumulation and release of nutrients by aquatic macrophytes. Symposium Biologica Hungarica 19: 33-42.

Kufel L, Strzałek M, Konieczna A, Izdebska K. 2010. The effect of Stratiotes aloides L. and nutrients on the growth rate of Lemna minor L. Aquatic Botany 92: 168-172.

Landolt E, Kandeler R. 1987. The family of Lemnaceae - a monographic study. Volume 2. Zurich: Veröffentlichungen des Geobotanischen Institutes der ETH

Lemon GD, Posluszny U, Husband BC. 2001. Potential and realized rates of vegetative reproductive in Spirodela polyrhiza, Lemna minor, and Wolffia borealis. Aquatic Botany 70: 79-87.

Lüönd AH. 1983. The family of Lemnaceae - a monographic study. Volume 3. Zurich: Veröffentlichungen des Geobotanischen Institutes der ETH. 
455 McClay CL. 1976. The effect of $\mathrm{pH}$ on the population growth of three species of duckweed: 456 Spirodela oligorrhiza, Lemna minor, and Wolffia arrhiza. Freshwater Biology 6: 125$457 \quad 136$.

458 Morris K, Bailey PC, Boon PI, Hughes L. 2003. Alternative stable states in the aquatic 459 vegetation of shallow urban lakes. II. Catastrophic loss of aquatic plants consequent to

461

462

463

464

465

466

467

468

469

470

471

472

473

474

475

476 nutrient enrichment. Marine \& Freshwater Research 54: 201-215.

Morris PF, Barker WG. 1977. Oxygen transport rates through mats of Lemna minor and Wolffia sp. and oxygen tension within and below the mat. Canadian Journal of Botany 55: 19261932.

Naeem S, Wright JP. 2003. Disentangling biodiversity effects on ecosystem functioning: Deriving solutions to a seemingly insurmountable problem. Ecology Letters 6: 567-579.

Netten JJC, Van Zuidam J, Kosten S, Peeters ETHM. 2011. Differential response to climatic variation of free-floating and submerged macrophytes in ditches. Freshwater Biology 56: $1761-1768$.

Peeters ETH, Van Zuidam JP, Van Zuidam BG, Van Nes EH, Kosten S, Heuts PGM, Roijackers RMM, Netten JCC, Scheffer M. 2013. Changing weather conditions and floating plants in temperate drainage ditches. Journal of Applied Ecology 50: 585-593.

Portielje R, Roijackers RMM. 1995. Primary succession of aquatic macrophytes in experimental ditches in relation to nutrient input. Aquatic Botany 50: 127-140.

R Development Core Team, 2013. R: A Language and Environment for Statistical Computing. R Foundation for Statistical Computing, Vienna, Austria. ISBN 3-900051-07-0. Available at: http://www.R-project.org. 
477 Rasband WS. 1997-2014. ImageJ. U. S. National Institutes of Health, Bethesda, Maryland, USA, $478 \quad$ Available at: http://imagej.nih.gov/ij/.

479 Scheffer M, Szabó S, Gragnani A, Van Nes EH, Rinaldi S, Kautsky N, Norberg J, Roijackers 480 RMM, Franken RJM. 2003. Floating plant dominance as a stable state. Proceedings of 481 the National Academy of Sciences of the United States of America 100: 4040-4045.

482

483

484 485

486 487

488

489

490

491

492

493

494

495

496

497

498

499 for developing countries. The World Bank, Washington, D.C.

Smart RM, Barko JW. 1985. Laboratory culture of submerged freshwater macrophytes on natural sediments. Aquatic Botany 21: 251-263.

Smith SDP. 2012. Identifying and evaluating causes of alternative community states in wetland plant communities. Oikos 121: 675-686.

Smith SDP. 2014. The roles of nitrogen and phosphorus in regulating the dominance of floating and submerged aquatic plants in a field mesocosm experiment. Aquatic Botany 112: 1-9.

Sterner RW, Elser JJ. 2002. Ecological Stoichiometry: The Biology of Elements from Molecules to the Biosphere. Princeton: Princeton University Press.

Szabó S, Roijackers R, Scheffer M. 2003. A simple method for analyzing the effects of algae on the growth of Lemna and preventing algal growth in duckweed bioassays. Archiv für Hydrobiologie 157: 567-575.

Szabó S, Roijackers R, Scheffer M, Borics G. 2005. The strength of limiting factors for duckweed during algal competition. Archiv für Hydrobiologie 164: 127-140.

Szabó S, Scheffer M, Roijackers R, Waluto B, Braun M, Nagy PT, Borics G, Zambran L. 2010. Strong growth limitation of a floating plant (Lemna gibba) by the submerged macrophyte (Elodea nuttallii) under laboratory conditions. Freshwater Biology 55: 681-690. 
500 Verdonschot RCM, Verdonschot PFM. 2013. Shading effects of free-floating plants on drainage501 ditch invertebrates. Limnology 15: 225-235.

502 Verma R, Suthar S. 2014. Synchronized urban wastewater treatment and biomass production $503 \quad$ using duckweed Lemna gibba L. Ecological Engineering 64: 337-343.

504 Xu J, Zhao H, Stomp A, Cheng JJ. 2012. The production of duckweed as a source of biofuels. 505 Biofuels 3: 589-601.

506 Ziegler P, Adelmann K, Zimmer S, Schmidt C, Appenroth K-J. 2015. Relative in vitro growth 507 rates of duckweeds (Lemnaceae) - the most rapidly growing higher plants. Plant Biology $508 \quad 17$ Suppl 1: 33-41.

509 
1

Effect of nutrients and temperature on relative growth rate (RGR) of three species of floating plants.

Error bars are standard errors. Post-hoc comparisons among species are for each response variable at each level of nutrients and temperature. Arrows indicate a species that is statistically different (Tukey's HSD $p>0.05$ ) at a given nutrient and temperature level. LM = Lemna minor, $\mathrm{SP}=$ Spirodela polyrhiza, and WB $=$ Wolffia brasiliensis
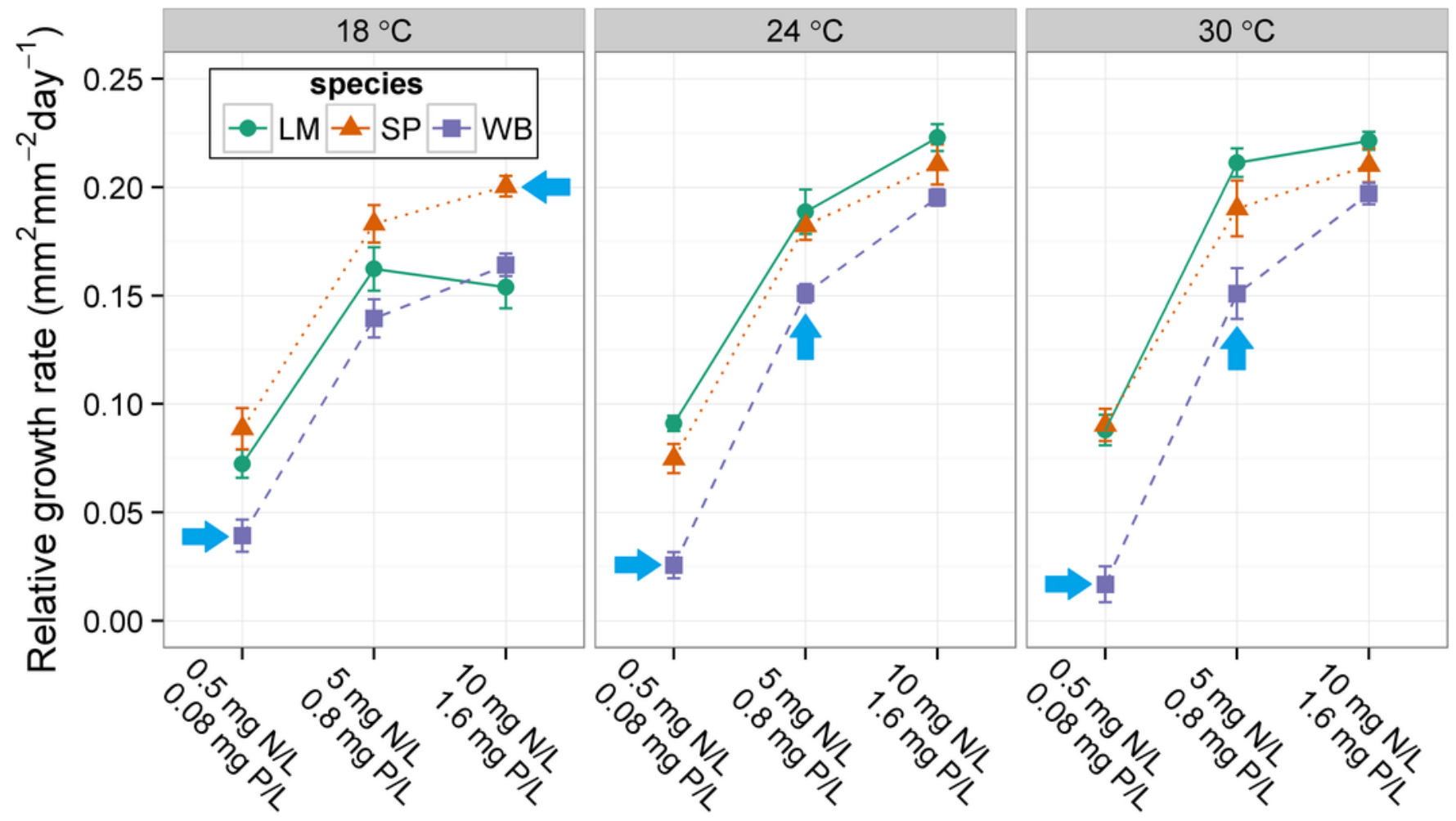

Nutrients 
2

Effect of nutrients and temperature on resting body formation.

Error bars are standard errors. Shared letters indicate no difference between treatment levels (Tukey's HSD p > 0.05) for W. brasiliensis turion production. LM = Lemna minor, SP = Spirodela polyrhiza, and WB $=$ Wolffia brasiliensis
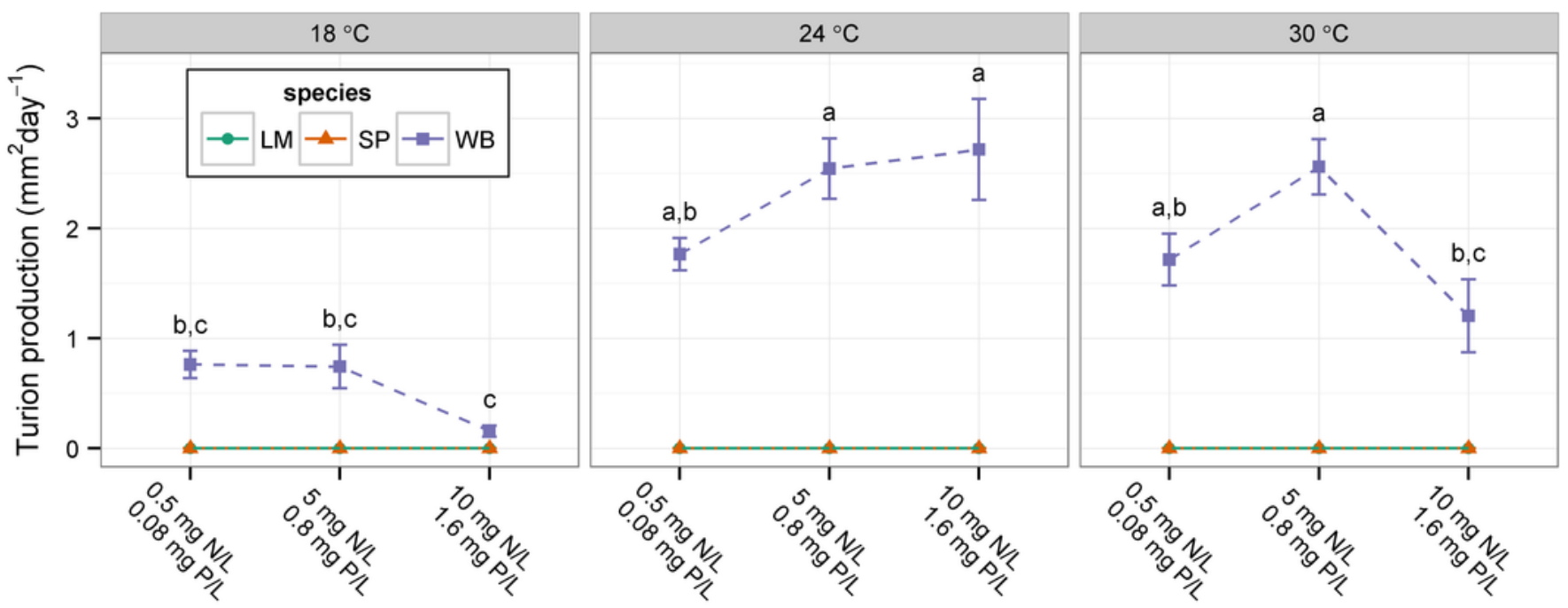

Nutrients 
3

Effect of nitrogen and phosphorus on relative growth rate (RGR) of three species of floating plants at $30^{\circ} \mathrm{C}$.

Error bars are standard errors. Post-hoc comparisons among species are for each response variable at each level of nitrogen and phosphorus. Arrows indicate a species that is statistically different (Tukey's HSD $p>0.05$ ) at a given nutrient and temperature level. N:P ratios are indicated in parentheses above the horizontal axis. $\mathrm{LM}=$ Lemna minor, SP $=$ Spirodela polyrhiza, and WB $=$ Wolffia brasiliensis

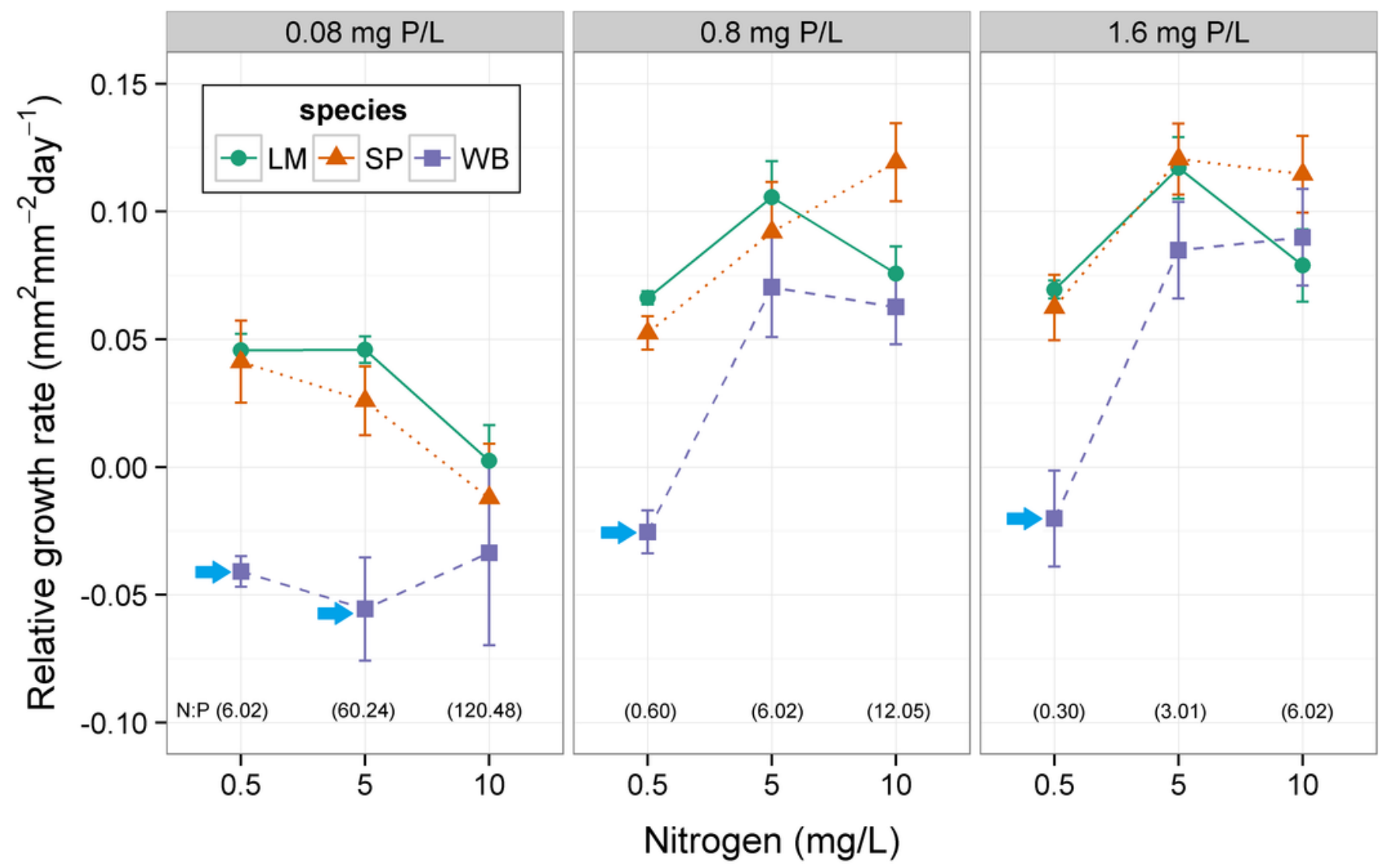


4

Effect of nitrogen and phosphorus on turion formation of three species of floating plants.

When more both L. minor and S. polyrhiza produced turions at a particular treatment level, significant differences between those species are indicated by unique letters (Tukey's HSD, $\mathrm{p}>0.05)$. Error bars are standard errors. $\mathrm{LM}=$ Lemna minor, $\mathrm{SP}=$ Spirodela polyrhiza, and WB $=$ Wolffia brasiliensis.

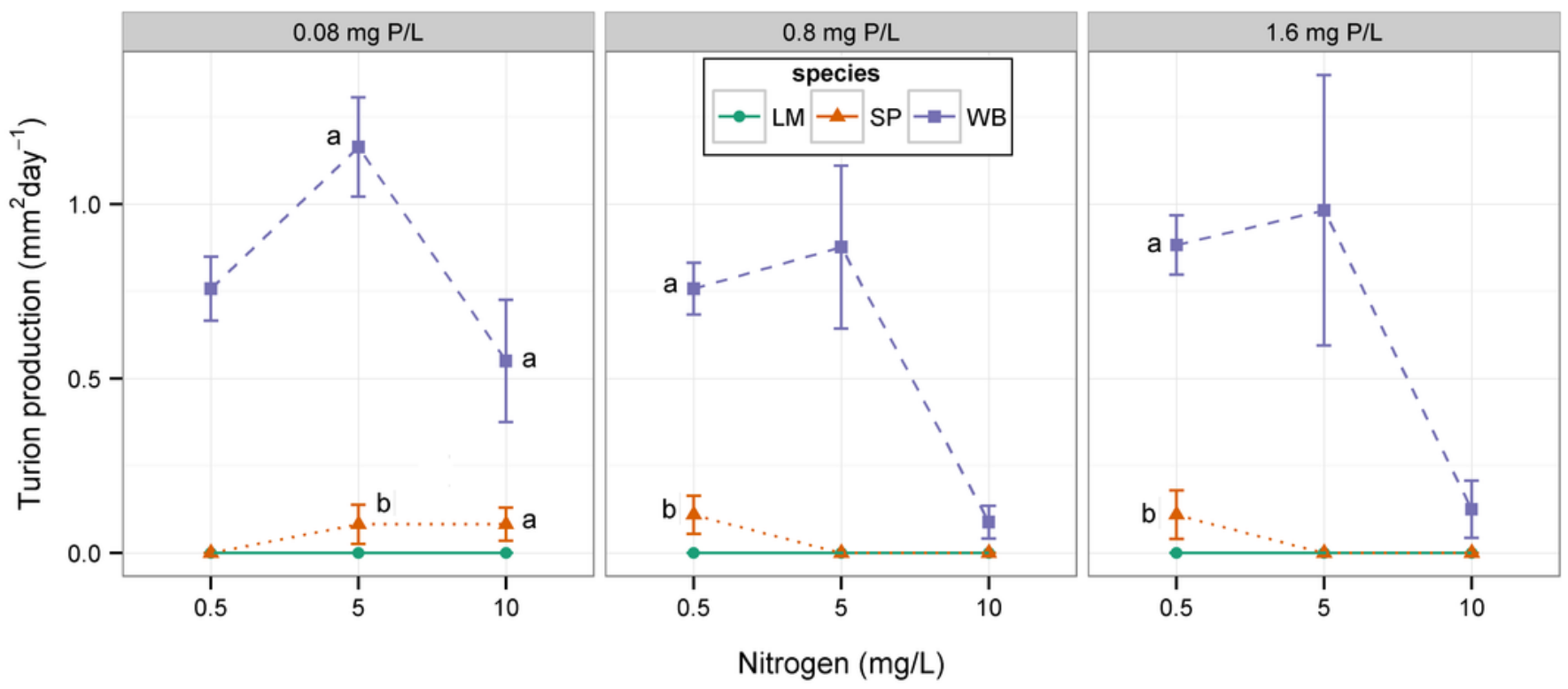




\section{5}

Floating plant species richness in lakes and ponds in Connecticut and Long Island, NY USA.

a) All water bodies with floating plants present $(n=99)$, and b) water bodies with floating plant cover $>66.67 \%$ of the water surface $(n=20)$. Dashed lines indicate expected value if random 

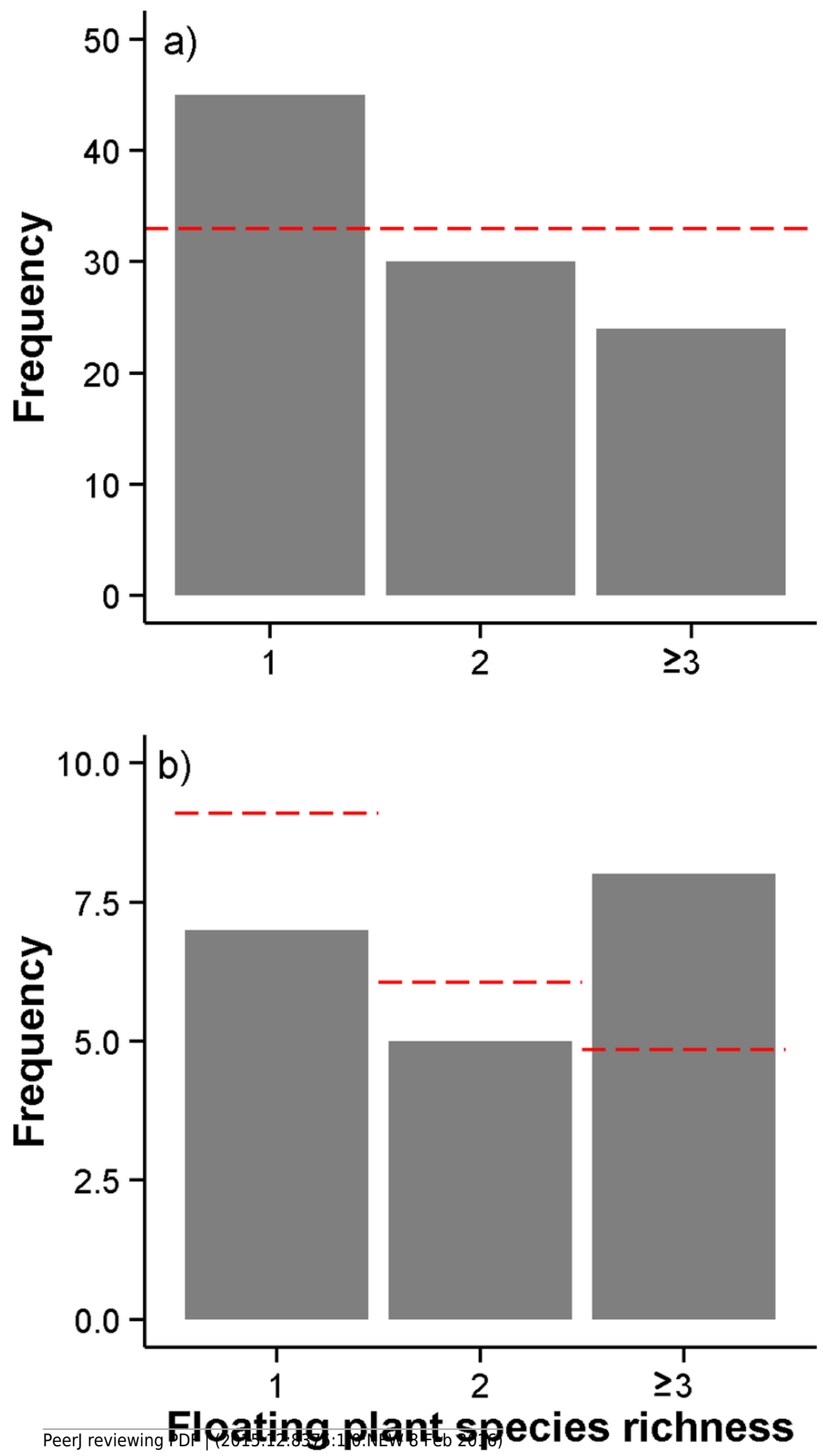


\section{Table $\mathbf{1}$ (on next page)}

$\mathrm{N}: \mathrm{P}$ mass ratios produced by nine combinations of nitrogen and phosphorus at $30{ }^{\circ} \mathrm{C}$ in Experiment II. 
1 Table 1. N:P mass ratios produced by nine combinations of nitrogen and phosphorus at $30{ }^{\circ} \mathrm{C}$ in

2 Experiment II.

3

\begin{tabular}{lrrrr} 
& & \multicolumn{3}{c}{ Nitrogen $\left(\mathrm{mg} \mathrm{L}^{-1}\right)$} \\
\cline { 3 - 5 } & & 0.5 & 5 & 10 \\
\cline { 3 - 5 } Phosphorus (mg L-1) & 0.083 & 6.02 & 60.24 & 120.48 \\
& 0.83 & 0.60 & 6.02 & 12.05 \\
& 1.66 & 0.30 & 3.01 & 6.02 \\
\hline
\end{tabular}

4 


\section{Table 2 (on next page)}

One-way ANOVAs for the effect of species on the average relative growth rate (RGR) of floating plants at nine combinations of nutrients and temperature. 
1 Table 2. One-way ANOVAs for the effect of species on the average relative growth rate (RGR)

2 of floating plants at nine combinations of nutrients and temperature.

\begin{tabular}{|c|c|c|c|}
\hline \multicolumn{2}{|c|}{ Treatment } & \multicolumn{2}{|c|}{ Average RGR } \\
\hline Nutrients & Temperature $\left({ }^{\circ} \mathrm{C}\right)$ & F-statistic & p-value \\
\hline \multirow[t]{3}{*}{ low } & 18 & 11.403 & $<0.001$ \\
\hline & 24 & 39.83 & $<0.001$ \\
\hline & 30 & 30.14 & $<0.001$ \\
\hline \multirow[t]{3}{*}{ medium } & 18 & 5.703 & 0.011 \\
\hline & 24 & 7.172 & 0.004 \\
\hline & 30 & 8.136 & 0.002 \\
\hline \multirow[t]{3}{*}{ high } & 18 & 12.44 & $<0.001$ \\
\hline & 24 & 4.106 & 0.031 \\
\hline & 30 & 4.325 & 0.027 \\
\hline
\end{tabular}

3

4 Note: Degrees of freedom for all ANOVAs were 2 and 21, except for at low nutrients and $30^{\circ} \mathrm{C}$,

5 where $\mathrm{df}=2,20$. Dunn-Šidák adjusted critical $p$-value is 0.0057 . Nutrient levels are low $=0.5$

$6 \mathrm{mg} \mathrm{N} \mathrm{L}{ }^{-1}$ and $0.083 \mathrm{mg} \mathrm{P} \mathrm{L}^{-1}$, medium $=5 \mathrm{mg} \mathrm{N} \mathrm{L}^{-1}$ and $0.83 \mathrm{mg} \mathrm{P} \mathrm{L}^{-1}$, or high $=10 \mathrm{mg} \mathrm{N} \mathrm{L}^{-1}$ 7 and $1.66 \mathrm{mg} \mathrm{P} \mathrm{L}^{-1}$. 


\section{Table 3(on next page)}

One-way ANOVAs for the effect of species on the average relative growth rate (RGR) of floating plants at nine combinations of nitrogen and phosphorus at $30^{\circ} \mathrm{C}$. 
1 Table 3. One-way ANOVAs for the effect of species on the average relative growth rate (RGR)

2 of floating plants at nine combinations of nitrogen and phosphorus at $30^{\circ} \mathrm{C}$.

\begin{tabular}{|c|c|c|c|}
\hline \multicolumn{2}{|c|}{ Treatment } & \multicolumn{2}{|c|}{ Average RGR } \\
\hline Nitrogen & Phosphorus & F-statistic & p-value \\
\hline \multirow[t]{3}{*}{ low } & low & 21.24 & $<0.001$ \\
\hline & medium & 60.61 & $<0.001$ \\
\hline & high & 14.1 & $<0.001$ \\
\hline \multirow[t]{3}{*}{ medium } & low & 14.08 & $<0.001$ \\
\hline & medium & 0.985 & 0.396 \\
\hline & high & 1.666 & 0.222 \\
\hline \multirow[t]{3}{*}{ high } & low & 0.506 & 0.613 \\
\hline & medium & 4.727 & 0.026 \\
\hline & high & 1.283 & 0.306 \\
\hline
\end{tabular}

3

4 Note: Degrees of freedom for all ANOVAs were 2 and 15. Dunn-Šidák adjusted critical p-value

5 is 0.005 . Nitrogen levels are low $=0.5 \mathrm{mg} \mathrm{N} \mathrm{L}^{-1}$, medium $=5 \mathrm{mg} \mathrm{N} \mathrm{L}^{-1}$, and high $=10 \mathrm{mg} \mathrm{N} \mathrm{L}^{-1}$.

6 Phosphorus levels are low $=0.083 \mathrm{mg} \mathrm{P} \mathrm{L}^{-1}$, medium $=0.83 \mathrm{mg} \mathrm{P} \mathrm{L}^{-1}$, and high $=1.66 \mathrm{mg} \mathrm{P} \mathrm{L}^{-1}$. 
Table 4 (on next page)

The frequency of floating plant species compositions and the frequency of floating plant cover exceeding two-thirds of the surface area of freshwater lakes and ponds in Connecticut and Long Island, NY. 
1 Table 4.The frequency of floating plant species compositions and the frequency of floating plant

2 cover exceeding two-thirds of the surface area of freshwater lakes and ponds in Connecticut and

3 Long Island, NY.

\begin{tabular}{|c|c|c|c|}
\hline $\begin{array}{l}\text { Floating plant } \\
\text { species richness }\end{array}$ & Species composition & $\begin{array}{l}\text { Frequency of } \\
\text { occurrence }\end{array}$ & $\begin{array}{l}\text { Frequency floating } \\
\text { plant cover }>66.67 \%\end{array}$ \\
\hline \multirow[t]{3}{*}{4} & A, LM, SP, W & 1 & 1 \\
\hline & $\mathbf{L M}, \mathrm{LV}, \mathbf{S P}, \mathbf{W}$ & 1 & 0 \\
\hline & $\mathbf{L M}, \mathrm{R}, \mathbf{S P}, \mathbf{W}$ & 1 & 0 \\
\hline \multirow[t]{4}{*}{3} & $\mathbf{L M}, \mathrm{LT}, \mathbf{S P}$ & 2 & 0 \\
\hline & $\mathbf{L M}, \mathbf{S P}, \mathbf{W}$ & 18 & 7 \\
\hline & $\underline{\mathrm{LT}, \mathbf{S P}, \mathbf{W}}$ & 1 & 0 \\
\hline & All $\geq 3$ species polycultures & 24 & 8 \\
\hline \multirow[t]{5}{*}{2} & $\mathrm{~A}, \mathbf{W}$ & 1 & 1 \\
\hline & $\mathbf{L M}, \mathbf{S P}$ & 14 & 2 \\
\hline & $\mathbf{L M}, \mathbf{W}$ & 13 & 2 \\
\hline & $\underline{\mathbf{S P}, \mathbf{W}}$ & 2 & 0 \\
\hline & All 2 species polycultures & 30 & 5 \\
\hline \multirow[t]{6}{*}{1} & A & 1 & 1 \\
\hline & $\mathbf{L M}$ & 32 & 4 \\
\hline & $\mathrm{LT}$ & 1 & 0 \\
\hline & SP & 7 & 0 \\
\hline & $\mathbf{W}$ & 4 & 2 \\
\hline & All monocultures & 45 & 7 \\
\hline \multirow[t]{2}{*}{0} & None & 106 & 0 \\
\hline & TOTAL & 205 & 20 \\
\hline
\end{tabular}

4

5 Note: $\mathrm{A}=$ Azolla sp., $\mathbf{L M}=$ Lemna minor, $\mathrm{LT}=$ L. trisulca, $\mathrm{LV}=$ L. valdiviana, $\mathrm{R}=$ Riccia sp.,

$6 \mathbf{S P}=$ Spirodela polyrhiza, $\mathbf{W}=$ Wolffia $\mathrm{sp}$. Taxa used in the laboratory experiments are

7 indicated by bold letters. 